
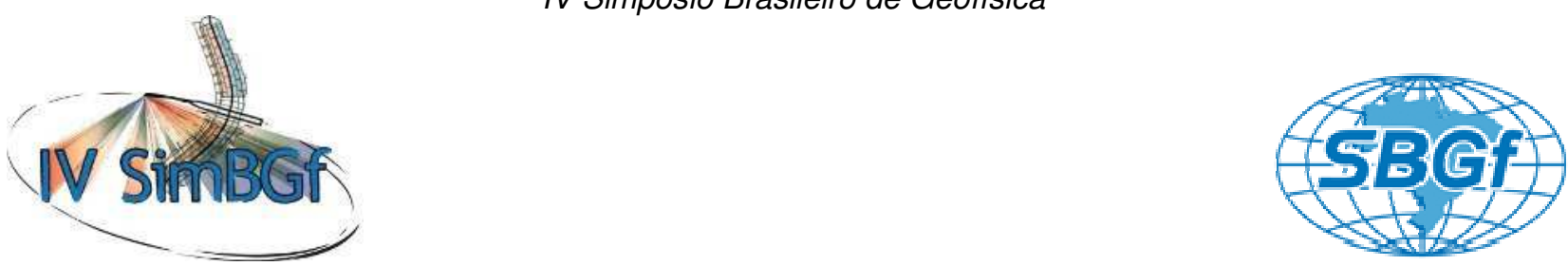

\title{
Assinaturas geofísicas do arcabouço estrutural da Bacia de Jaibaras - NE do Brasil
} PEDROSA JÚNIOR, Nilo Costa (1), DE CASTRO, David Lopes (2), CASTELO BRANCO, Raimundo Mariano Gomes (1), FUCK, Reinhardt Adolfo (3).

(1) Universidade Federal do Ceará, E-mail: nilojuniorp@yahoo.com.br; (2) Universidade Federal do Rio Grande do Norte; (3) Universidade de Brasília.

Copyright 2010, SBGf - Sociedade Brasileira de Geofísica

Este texto foi preparado para a apresentação no IV Simpósio Brasileiro de Geofísica, Belém, 14 a 17 de novembro de 2010. Seu conteúdo foi revisado pelo Comitê Técnico Belem, 14 a 17 de novo para a apresentaça no 2010 . Seu conteúdo toi revisado pelo Comie Ténico do IV SimBG, mas nao necessanamente representa a opinia da SBGr ou de seus

\section{Abstract}

Gravity, magnetic and radiometric signatures of the Jaibaras Basin, NW Borborema Province (NE Brazil) are presented in this work. A qualitative interpretation of the potential filed datasets allowed the characterization of five geophysical domains for the basin structural framework, which can be correlated with major regional tectonic blocks.

\section{Introdução}

Diversos estudos geológicos realizados na região noroeste do Ceará nos últimos 50 anos têm demonstrado que esta área é uma das mais interessantes e complexas do país, principalmente, no que diz respeito à sua evolução geológica (Oliveira \& Mohriak, 2003). Entendimento fundamental sobre as relações entre a deformação distensional, a estruturação pretérita, reativações de estruturas do embasamento e a arquitetura do rifte resultante pode ser obtido por meio da interpretação integrada de dados gravimétricos, magnéticos e radiométricos. Com isso, o objetivo principal da pesquisa é mapear o arcabouço estrutural da Bacia de Jaibaras e cartografar os eventos magmáticos, com base nas suas assinaturas geofísicas.

A área pesquisada situa-se na região nordeste do Brasil, mais especificamente no extremo NW do Ceará, envolvendo as rochas associadas à Bacia de Jaibaras e seu arcabouço tectônico. É limitada pelas coordenadas geográficas $-41^{\circ}$ e $-40^{\circ}$ de longitude oeste e -420' e -3ํㅡㄴ de latitude sul (Figura 1).

\section{Contexto Geológico Regional}

O Rifte de Jaibaras (Figura 1) é a mais importante bacia de idade Cambro-Ordoviciana que ocorre em terrenos Pré-cambrianos da Província Borborema e do Escudo Nigeriano (Oliveira, 2001). Situa-se no limite entre dois domínios crustais distintos: (1) Ceará Central (DCC), localizado na porção sudeste da área, caracterizado pela presença de rochas metamórficas de médio a alto grau, arqueanas e paleoproterozóicas, sequências de rochas supracrustais neoproterozóicas, extenso complexo granítico-migmatítico (Fetter et al., 2003), além de intenso plutonismo sin-, tardi- e pós-tectônico; e (2) Médio Coreaú (DMC), que é limitado, a sudeste, pela Zona de Cisa-
Ihamento Sobral-Pedro II (ZCSPII), parte do Lineamento Transbrasiliano, e é constituído por rochas do embasamento gnáissico paleoproterozóico, sequências supracrustais neoproterozóicas (rochas metamórficas de médio a alto grau), além de granitóides intrusivos situados próximos a rochas vulcano-sedimentares de bacias paleozóicas, como a Bacia de Jaibaras.

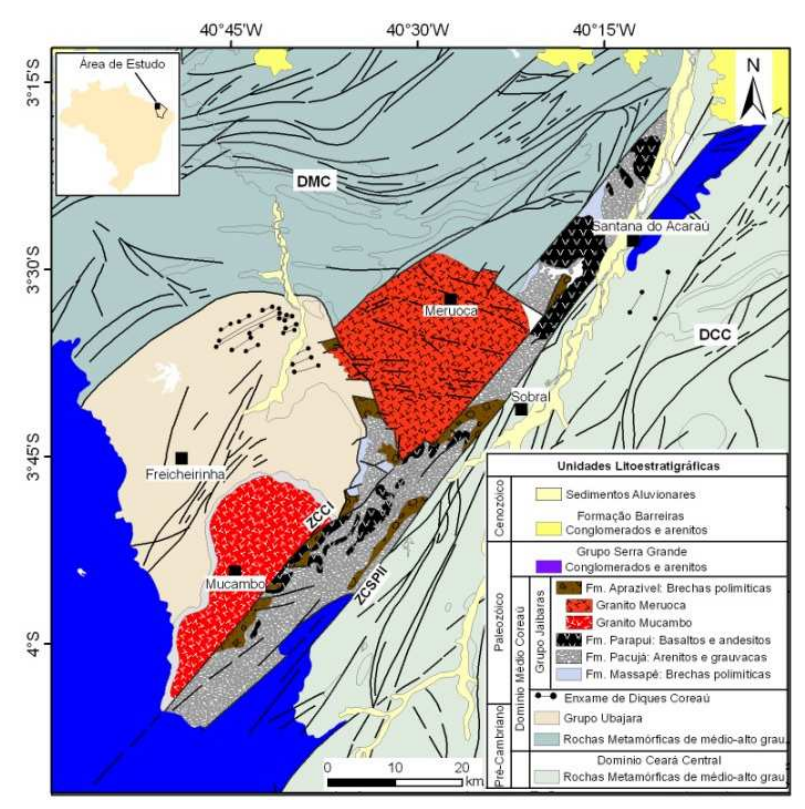

Figura 1 - Mapa geológico simplificado da Bacia de Jaibaras. Domínios Crustais: DCC - Ceará Central, DMC Médio Coreaú; Zonas de Cisalhamento: ZCSPII - SobralPedro II, ZCCI - Café-Ipueiras (Escala - 1:500.000; CPRM, 2003). Datum: SAD-69, zona 24 Sul.

O Grupo Ubajara (Figura 1) é caracterizado por ciclo tectono-sedimentar completo em margem continental, apresentando litofácies psamíticas proximais e distais com passagens laterais e interdigitadas. Apresenta uma sequência metacarbonática marinha, culminando em sequência metarcosiana e metagrauváquica.

O Enxame de Diques Coreaú constitui-se de rochas de composição ácida (dacitos e riolitos), com porções isoladas de xenólitos de rochas básicas. Apresentam-se de forma descontínua e subparalelos, com direção principal N80E e mergulho subvertical.

A estratigrafia da Bacia de Jaibaras é marcada por duas sequências distintas: (1) Alfa Inferior, representada pelas 
Formações Massapê, Pacujá e Suíte Parapuí (Figura 1); e (2) Alfa Superior, representada também pela suíte Parapuí e pela Formação Aprazível (Parente et al,. 2004). Segundo Oliveira \& Mohriak (2003), o final da deposição seria marcado pelo início da sedimentação da Bacia do Parnaíba no Eosiluriano (Grupo Serra Grande). O granito Meruoca é intrusivo na sequência Alfa inferior. Desta forma se pode inferir uma idade mínima para a sequência Alfa inferior entre 560 e 540 Ma e uma idade máxima para a sequência Alfa superior entre 540 e 440 Ma.

No extremo norte da área afloram depósitos sedimentares de composição areno-argilosa, associados à Formação Barreiras (Figura 1). Os sedimentos aluvionares são constituídos de blocos e seixos de rochas ou quartzo, associado a areias quartzosas.

\section{Origem dos Dados}

O NW do Ceará apresenta uma cobertura gravimétrica de 670 estações de medidas. Esses dados foram levantados pela Universidade Federal do Pará, Observatório Nacional e Instituto Brasileiro de Geografia e Estatística (IBGE). A Figura 2 apresenta o mapa de anomalias Bouguer com a distribuição das estações de medidas na área pesquisada.



Figura 2 - Mapa de Anomalias Bouguer, com a distribuição das estações gravimétricas.

O conjunto de dados aerogeofísicos (magnetometria e gamaespectrometria) foram levantados pela Petrobras, no âmbito do Projeto Rio Acaraú em 1975, cobrindo uma área de $21.000 \mathrm{~km}^{2}$ no NW do Ceará (Figura 3). As linhas de voo possuem direção N-S, com espaçamento entre elas de cerca de $1,0 \mathrm{~km}$, intervalo de amostragem de $2 \mathrm{~s}$ e uma altitude média em relação ao terreno de $150 \mathrm{~m}$.
As correções da atração luni-solar, latitude, elevação e Bouguer foram previamente efetuadas no conjunto de dados gravimétricos. O mapa de anomalias Bouguer (Figura 2) foi confeccionado por meio da interpolação dos dados em malha regular de $1 \mathrm{~km}$, utilizando o método kriging. As componentes regional e residual do campo gravimétrico (Figuras $4 a$ e $4 b$ ) foram separadas por meio de um filtro de separação regional-residual, que se baseia na distribuição gaussiana das fontes gravimétricas em função de suas profundidades.

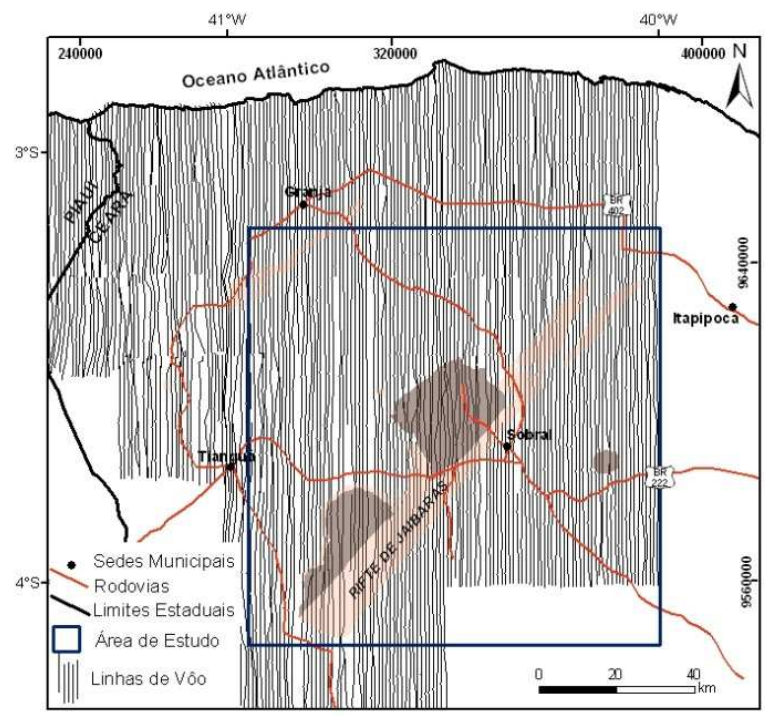

Figura 3 - Mapa com a distribuição das linhas vôo do Projeto Rio Acaraú.

Os dados aeromagnéticos foram corrigidos da variação diurna e da variação da componente principal do campo geomagnético (IGRF). Tais dados foram interpolados em malha regular de $500 \mathrm{~m}$, pelo método kriging. Foi aplicado processamento digital com o intuito de identificar e delimitar as estruturas geológicas regionais, compreendendo: a) Filtro azimutal, empregado para eliminar ruídos de alta frequência segundo as linhas de voo; b) Filtro de redução ao pólo (Figura 4c), usado para centralizar as anomalias sobre suas devidas fontes; e c) Sinal analítico 3-D (Figura 4d), que utiliza as derivadas horizontal e vertical para realçar as bordas ou contatos das feições geológicas e falhas. Os dados radiométricos foram interpolados, também pelo método kriging, em malha de 500 $\mathrm{m}$, e foram realizados procedimentos para atenuação do ruído ao longo das linhas de vôo.

\section{Interpretações}

As anomalias gravimétricas regionais apresentam gradiente gravimétrico que varia de $-50 \mathrm{mGal}$ a valores próximos de $1 \mathrm{mGal}$, no sentido de Sul para Norte. Esse aumento contínuo do campo gravimétrico é ocasionado pelo afinamento crustal característico da margem continental passiva do Nordeste brasileiro, com eixo principal na direção NNE-SSW, como mostra a seta da Figura 4a.

Apesar da baixa cobertura gravimétrica (Figura 2), o mapa de anomalias residuais resultante (Figura 4b) apresenta boa correlação com as principais feições geológi- 
cas do DMC (Figura 1). Cinco domínios gravimétricos podem ser individualizados, sendo a ZCSPII o principal delimitador entre o mínimo gravimétrico da região do DCC, no sudeste da área, e as anomalias predominantemente positivas do DMC, a noroeste.

A interpretação qualitativa dos dados aerogeofísicos foi conduzida com base na assinatura geofísica dos cinco domínios magnéticos e radiométricos e no contexto geológico de superfície da área de estudo (Figura1).

O Rifte de Jaibaras destaca-se por fortes anomalias positivas em seu interior (Figura 4c), onde afloram rochas sedimentares das formações Massapé, Pacujá e Aprazível e rochas vulcânicas (Formação Parapuí). O DMC é dominado por intensos lineamentos magnéticos, de direção E-W que sofrem leve inflexão para NE-SW, com padrão de anomalias alongadas de curto comprimento de onda, que estão associadas aos alinhamentos estruturais do embasamento cristalino. Os granitos Meruoca e Mocambo possuem relevo magnético intermediário (-25 a $25 \mathrm{nT}$ ), como pode ser observado no mapa de anomalias reduzidas ao pólo (Figura 4c) e caracterizam-se pela ausência de sinal analítico 3-D em seu interior (Figura 4d). As rochas ácidas do Enxame de Diques Coreaú estão associadas a uma forte anomalia negativa (-70 nT). A porção sudeste da área, que corresponde às rochas do DCC, caracteriza-se por relevo magnético isotrópico, com anomalias de longo comprimento de onda e ausência do sinal analítico 3-D (Figura $4 d)$.

No levantamento gamaespectrométrico foram medidos quatro canais radiométricos: Potássio, Urânio, Tório e Contagem Total (CT). O mapa de anomalias de CT (Figura 4e) fornece uma boa informação sobre as unidades litológicas da área, bem como os lineamentos estruturais do embasamento cristalino. O Rifte de Jaibaras possui relevo radiométrico bem inexpressivo, com baixos valores de contagem em todos os canais, sem a presença de qualquer feição importante. O DMC é representado por baixos valores de contagem ( 0 a 300 cps) em toda a porção norte da região. A intrusão plutônica de Meruoca possui altos valores radiométricos, principalmente nas bordas. O Granito Mocambo é, também, caracterizado por altos valores de contagem, principalmente na porção norte, com picos que chegam a atingir $1.000 \mathrm{cps}$. As rochas do Grupo Ubajara e do Enxame de Diques Coreaú possuem valores médios de contagem, sendo bem marcado ao norte o contato com as rochas do embasamento. O DCC é marcado por anomalias intermediárias (600-800 cps), com caráter bastante anisotrópico. Percebe-se também forte anomalia de forma alongada, que se estende desde o nordeste até o sul da área, que está relacionada a sedimentos aluvionares (Figura 4e).

A cartografia geofísica dos referidos domínios geofísicos (Figura 4f) fornece importantes subsídios para a distribuição espacial das unidades geológicas que formam 0 substrato estrutural do Rifte de Jaibaras, bem como os principais lineamentos estruturais da região.

\section{Conclusões}

O estudo das assinaturas geofísicas do arcabouço estrutural da Bacia de Jaibaras forneceu ótima correlação com as unidades e estruturas geológicas da região. Os resultados obtidos no presente trabalho permitiram as seguintes conclusões acerca da região:

- A interpretação do mapa de anomalias gravimétricas possibilitou reconhecer o eixo principal na direção NE SW, com alternância de máximos e mínimos no DMC;

- A inflexão no mapa regional de anomalias gravimétricas demonstra importante variação lateral de densidade entre os domínios DMC e DCC, ressaltando a importância da ZCSPII como principal zona de sutura continental entre estes blocos crustais;

- Os mapas aeromagnéticos mostram estruturação regional marcada por lineamentos magnéticos com direção E-W e leve inflexão para NE-SW no DMC e direção NESW no interior do Rifte de Jaibaras. Já o DCC é marcado por caráter mais isotrópico;

- Os principais lineamentos geofísicos possuem direções preferenciais NE-SW e E-W e subordinados de direção NW-SE (Figura 4f). A assinatura das fontes geofísicas apresenta cinco domínios, sendo bem correlacionados com a geologia de superfície e os principais blocos crustais da região.

\section{Referências Bibliográficas}

CPRM (Serviço Geológico do Brasil), 2003. Mapa Geológico do Estado do Ceará em escala de 1:500.000. Formato digital: shapefile (ESRI).

Fetter, A.H; Dos Santos, T.J.S.; Van Schmus, W.R.; Hackspacher, P.C.; Brito Neves, B.B.; Arthaud, M.; Nogueira Neto, J.A.; Wernick, E. 2003. Evidence for Neoproterozoic continental arc magmatism in the Santa Quiteria Batholith of Ceará State, NW Borborema Province, NE Brasil: Implications for the assembly of west Gondwana. Gondwana Research, 6 (2): 265-273.

Oliveira, D.C., 2001, Reavaliação da evolução tectonomagmática do Gráben de Jaibaras (Nordeste do Brasil). Acta Geológica Hispânica, 36 (1-2): 53-95.

Oliveira, D.C ,, Mohriak, W.U, 2003. Jaibaras trough: an important element in the early tectonic evolution of the Parnaíba interior sag basin, Northern Brazil, Marine and Petroleum Geology 20 (2003) 351-383.

Parente, C. V., Silva Filho, W. F., Almeida, A. R., 2004. Bacias do Estágio de Transição do Domínio Setentrional da Província Borborema. In: Mantesso Neto, V., Bartorelli, A., Carneiro, C.D.R., Brito Neves, B.B.). O Desvendar de um Continente: A Moderna Geologia da América do Sul e o Legado da Obra de Fernando Flávio Marques de Almeida. São Paulo, Beca, p. 526 536. 


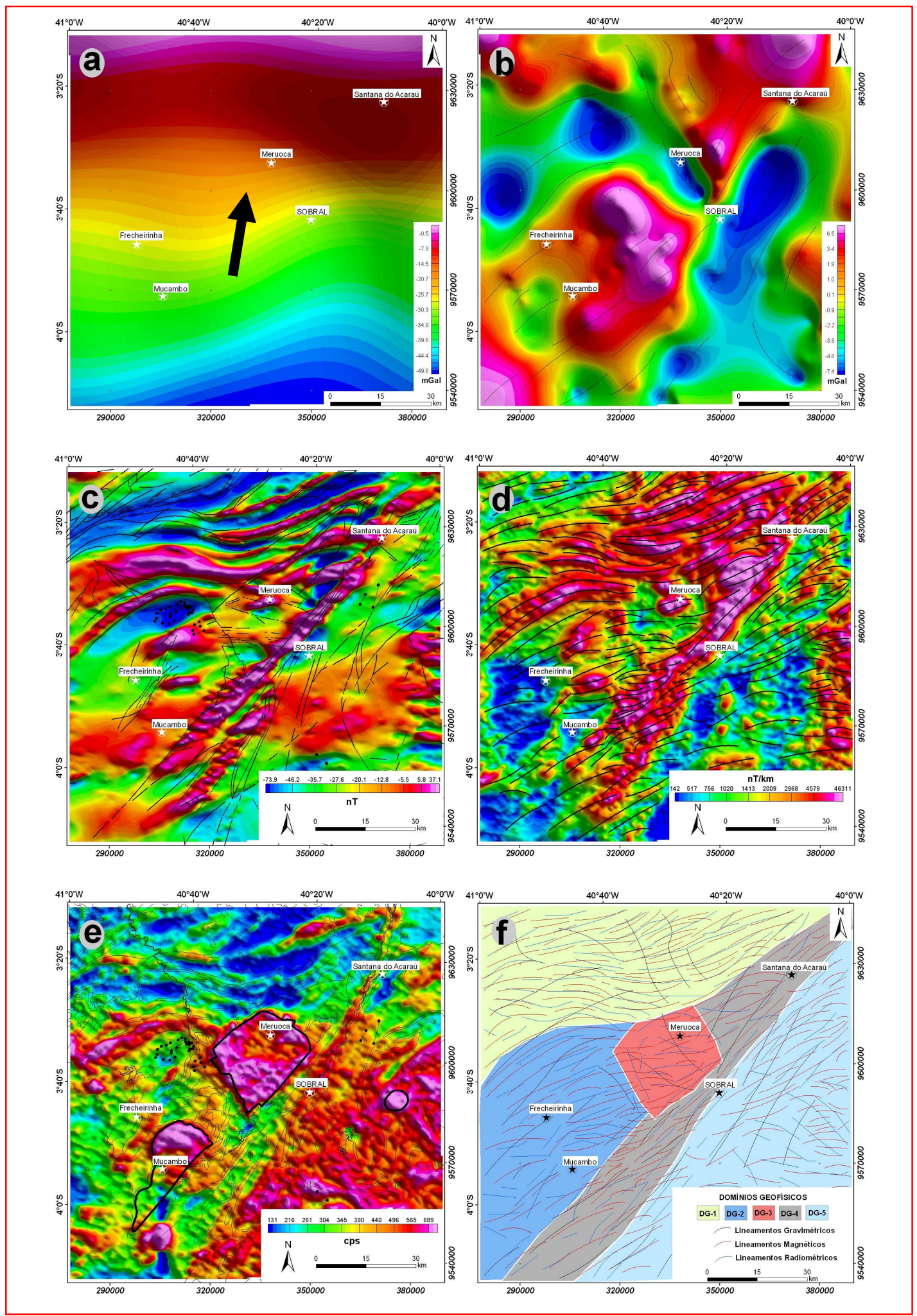

Figura 4 - Mapa de Anomalias: (a) Gravimétricas Regionais; (b) Gravimétricas Residuais, com os principais lineamentos gravimétricos; (c) Magnéticas Reduzidas ao Pólo, com os principais falhamentos e diques aflorantes; (d) Magnéticas do Sinal Analítico 3-D, sobrepostas aos principais alinhamentos magnéticos; (e) Radiométricas (Contagem Total), sobrepostas à geologia de superfície; e (f) Mapa Geofísico Interpretado. 